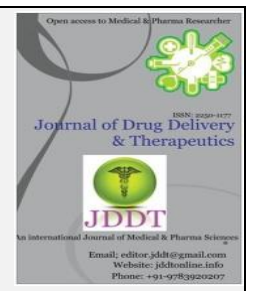

\title{
Formulation and Evaluation of Anti-Acne Face Wash Gel using Guava Seed Extract
}

\author{
Kamble Manish*, Selwate Tejaswini, Dhabarde Disha, Ingole Ashwini, Baheti Jagdish
}

Kamla Nehru College of Pharmacy, Butibori, Nagpur (M.S.) 441108. India.

\begin{abstract}
During the puberty, imbalance of internal constituents and hormonal balance may cause many skin problems. Acne is found as most common skin problem. Face and neck are the major affected area. Preventive approaches involve removal of oil from the face. Proper cleaning and washing require for this purpose. Various researches have been proved utility of herbal based formulations for cleaning purpose which also removes excess oil; considering this fact present work was intended to prepare a face wash gel using Psidium guajava seed extract with antioxidant and antibacterial properties. Prepared gel was evaluated for various quality control parameters like; spreadability, pH, consistency and grittiness, etc. The results of quality control parameters were found to be satisfactory.
\end{abstract}

Keywords: Acne, Gel, Antimicrobial, Psidium guajava, Face-wash

Article Info: Received 15 March 2019; $\quad$ Review Completed 20 April 2019; $\quad$ Accepted 22 April 2019; Available online 15 May 2019

\section{Cite this article as:}

Kamble M, Selwate T, Dhabarde D, Ingole A, Baheti J, Formulation and Evaluation of Anti-Acne Face Wash Gel using Guava Seed Extract, Journal of Drug Delivery and Therapeutics. 2019; 9(3):5-7

http://dx.doi.org/10.22270/jddt.v9i3.2595

*Address for Correspondence:

Kamla Nehru College of Pharmacy, Butibori, Nagpur, (M.S.) 441108, India

\section{INTRODUCTION}

The herbal healing has been mentioned from the ancient era, from Vedas, and even from ancient religious work. Probably it is the oldest medical care system in the world. The herbal healing deals with use of herbs, herbs extracts or natural products for the betterment of health condition. Nowadays in westerns countries medical practitioners and mostly prescribing medicines containing plant extract. Developed countries also appreciating this traditional and ancients form of medicine. As a result, Indian herbal drugs are in demand and witnessing rapid growth in global market. Wide growth and demand for herbal cures, herbal skin care products and even herbal cosmetics were observed in recent years ${ }^{1}$. Although, herbal products are more acceptable with belief that they are safe posses many therapeutic properties and having no or less side effects as comparing to modern chemical entities. Skin being the most exposed and major part of our body to the pathogens. Hence require protection and prevention from skin diseases by utilization of formulations having antibacterial, antioxidant and anti inflammatory and such other properties. During the puberty imbalance of internal constituents and hormonal balance may cause many skin problems. Acne is found as most common skin problem which is generally characterized $b$ presence of inflammatory lesions, comedon, seborrhea etc. acne may cause long lasing, physical and detrimental psychosocial effect associated with depression and anxiety without disease severity. Although these effects usually improved by treatment. Acne develop in presence of commensally bacteria Propionibactum acne, Staphylococcus epidermadis and Malassezia furfur in the follicles. Long term uses of antibiotics for the treatment develop resistance to the drugs. To overcome this problem, herbal alternative solution for the treatment has been studied.

Psidium guajava Linn, a well known traditional medicinal plant used in various indigenous system of medicine, also known as Guava belonging to family Myrtaceae. It is represented by approximately $130-150$ species $^{2}$ and widely distributed throughout the world ${ }^{3}$. All parts of the plants being used as medicine, the parts like fruits, leaves, bark and root have been used to treat diarrhea and used as stomachache, respiratory and gastrointestinal disorders as antispasmodic, anti- inflamatory, as cough sedative, in obesity, to control diabetes mellitus. Seeds possess antimicrobial4, anti inflammatory ${ }^{5}$, anti allergic ${ }^{6}$, and anti carcinogenic activity ${ }^{7}$. Guava is yellow in color and owing to its abundance and reasonable price it is eaten by all sector by the society.The main guava fruit product are beverages, juices, and canned slices. The important constituents of guava are vitamins ${ }^{8}$, tannins, phenolic compounds, essential oils sesquiterpene alcohol and triterpenoids. The seed are the waste product of the industry and are not yet use for the 
any beneficial purpose. Guava seed have been reported to contain $14 \%$ oil, $15 \%$ protein and $13 \%$ starch 9 . It also contains flavonoids. Among these phytochemicals phenolic compounds are the most common in nature 10 .

\section{MATERIAL AND METHOD}

Collection of Plant Materials: The fruits of Psidium guajava were collected from college campus of Kamla Nehru College of Pharmacy, Butibori, Nagpur Maharastra. Plant material was identified and authenticated in the department of Botany, RTM Nagpur University Nagpur, Maharashtra. The collected materials were cleaned and flesh was removed for further processes of separation of seeds and extraction.

Preparation of the Extract: Seeds were taken (100g) and subjected to alcoholic extraction (Soxhlet Extraction) then, rate was allowed to evaporate excess of solvent under rotary vacuum evaporator until clear liquid (Oil) is obtained. Then the oil extract was then re-dissolved in ethanol at $1 \mathrm{mg} / \mathrm{ml}$ ratio and used for formulating the Face wash gel.

Preparation of Gel Base: A little quantity of water along with preservatives was added to the previously prepared solution of propylene glycol and sodium lauryl sulphate, then carbopol was added slowly and stirred well until a gel like dispersion was obtained, Various gel formulations were prepared on the basis of quantity of ingredient of HPMC and Carbapol 940.11 to this the stock solution of seed extract was added, and then triethanolamine was added finally and left for overnight 12 .

Evaluation of prepared gel: The physical properties such as color, appearance and consistency were determined visually. Viscosity was measured using the Brook Field Viscometer (Ottendorf, Germany) ${ }^{13}$ and $\mathrm{pH}$ of $1 \%$ aqueous solution of the formulation was measured by using a calibrated digital $\mathrm{pH}$ meter at constant temperature. Spreadability is the property of gel to spread uniformly and smoothly in maximum area of affected part. The bioavailability efficiency of a gel formulation also depends on its spreading value. The spreadability is expressed in terms of time in seconds taken by two slides slip off from the gel, placed in between the slides, under certain load. The spreadiability is good if the slipping time is less. Two sets of glass slides of standard dimensions were taken. The herbal gel formulation was placed over one of the slides. The other slide was placed on the top of the gel, such that the gel was sandwiched between the two slides in an area occupied by a distance of $6 \mathrm{~cm}$ along the slide. A $30 \mathrm{gm}$ weight was tied to the upper slide carefully. The time taken for the upper slide to travel the distance of $6 \mathrm{~cm}$ and separated away from the lower slide under the influence of the weight was noted. The experiment was repeated three times both formulated gels and marketed gel and the mean time taken for calculation.

\section{Formula: $\mathrm{S}=\mathrm{M} \times \mathrm{L} / \mathrm{T}$}

Where, S=Spreadability, M= Mass in gm (30gm), L=Length of the glass $(6 \mathrm{~cm}), \mathrm{T}=$ Time in sec.

The washability was determined using formulation already applied on skin and then ease and extent of washing with water were checked manually. Washability was determined by applying gel on hands and exposed to running water. Foamability also determined by taking Small amount of gel in a beaker containing water. Initial volume was noted, beaker was shaken for 10 times and the final volume was noted. Grittiness of the gel was checked for the presence of any gritty particles by applying it on the skin. The stability of the gels was tested using freeze thaw cycling method. The gels were subjected to a temperature of $4^{\circ} \mathrm{C}$ for 7 days, $25^{\circ} \mathrm{C}$ for 7 days and then at $40^{\circ} \mathrm{C}$ for 7 days ${ }^{15}$. The gels were exposed to the ambient room temperature.

Determination of antimicrobial activity of anti-acne face wash gels against acne causing microorganisms:

Turbidimetric method was used for the screening of antimicrobial activity. A sterile nutrient agar medium was prepared and spread on a Petri plate aseptically. The skin on the face of a volunteer with distinctive acnes was washed with distilled water and let to dry. Then a cotton swab was rubbed on the ruptured pimple till its entire surface touched the acne and it was soaked in $5 \mathrm{ml}$ of distilled water. This solution was evenly poured on to the previously prepared medium. This was incubated for $24 \mathrm{hr}$ at $37^{\circ} \mathrm{C}$ to get a good culture of microorganism

Six sterile cotton balls of $1 \mathrm{~cm}$ diameter were soaked in prepared formulations standard drug and distilled water for $5 \mathrm{~min}$. Nutrient broth (50 ml) was prepared and sterilized; 5 $\mathrm{ml}$ was kept aside and was used as reference standard in one cell of the UV spectrophotometer. The remaining broth was inoculated with the organism cultured in the Petri plate. This inoculated broth $5 \mathrm{ml}$ was poured into six sterile test tubes and the cotton balls were suspended in each of the test tube and marked accordingly. They were incubated for $24 \mathrm{~h}$ at $37^{\circ} \mathrm{C}$ in an incubator. Then they were taken out and checked for the absorbance at $600 \mathrm{~nm}$.

\section{RESULTS AND DISCUSSIONS}

The different gel formulation of Psidium guajava seed oil was prepared using various ingredients as mentioned in Table 1. The formulation was prepared trial \& error basis until a gel was obtained with characteristic feature. The Psidium guajava utilized as chief ingredient since individually it is possess all essential of properties of face wash formulation like; antioxidant and antimicrobial properties. The various other ingredients used for specific purpose like; Carbopol 940 as gelling agent, Methyl Paraben \& Propyl Paraben as preservatives, Triethanolamine as neutralizer, Propylene Glycol as Humectant and Sodium Lauryl Sulphate as Foaming agent. Finally volume of formulation was adjusted with distilled water. The formulation was also evaluated for various quality parameters and results of quality parameters revealed that formulation possess all desire quality parameters as mentioned in Table 2. Formulation showed $\mathrm{pH}$ with range of skin application, it also showed characteristic consistency of gel, viscosity was found to be $5549 \mathrm{cp}$. Finally homogenous, spreadable and washable formulation was obtained without any grittiness. Stability studies were performed and the results were tabulated in Table 3. The results showed that the gels stood stable at all temperatures with a little change. The efficacy of the antiacne gels from herbal extracts is shown in Table 4. The antiacne gels could inhibit the growth of the microorganisms that inhabit acnes and all the formulations exhibited comparatively less efficacy to standard drug.

Table 1: Composiion of gel formulaions $(\% \mathrm{w} / \mathrm{w})$

\begin{tabular}{|l|l|l|}
\hline S. N. & Ingredient & Quantity \\
\hline 1 & Drug extract & 4 \\
\hline 2 & Carbapol & 1.5 \\
\hline 3 & Methyl paraben & 0.1 \\
\hline 4 & Propile paraben & 1 \\
\hline 5 & Triethanolamine & 2 \\
\hline 6 & Propylene Glycol & 2.5 \\
\hline 7 & Sodium lauryl Sulphate & 2.5 \\
\hline 8 & Water & QS \\
\hline
\end{tabular}


Table 2: Quality parameters of Gel formulation

\begin{tabular}{|l|l|l|}
\hline S. N. & Parameters & Observations \\
\hline 1 & Colour & Transparent \\
\hline 2 & Odour & None \\
\hline 3 & Consistency & Consistent \\
\hline 4 & pH & 5.9 \\
\hline 5 & Viscosity (cp) & $5549 c p$ \\
\hline 6 & Spreadability (gm.cm/sec) & 1.8 \\
\hline 7 & Washability & Washable \\
\hline 8 & Foamability & Passed \\
\hline 9 & Grittiness & Nil \\
\hline
\end{tabular}

Table 3: stability studies of the formulation

\begin{tabular}{|l|l|l|l|l|l|l|}
\hline \multirow{2}{*}{ Formulation } & \multicolumn{2}{|l|}{ pH } & \multicolumn{2}{l|}{ Viscosity } \\
\cline { 2 - 7 } & $4^{0} \mathrm{c}$ & $2^{\circ} \mathrm{c}$ & ${40^{\circ}}^{\circ} \mathrm{c}$ & $4^{0} \mathrm{c}$ & $2^{\circ} \mathrm{c}$ & $4^{\circ} \mathrm{c}$ \\
\hline Gel & 5.9 & 5.9 & 5.8 & 5549 & 5578 & 5506 \\
\hline
\end{tabular}

Table 4: Anti-acne efficacy of formulations

\begin{tabular}{|l|l|}
\hline Formulation & Absorbance \\
\hline Gel formulation & $\mathbf{0 . 1 4 3 8}$ \\
\hline Standard & $\mathbf{0 . 1 2 7 1}$ \\
\hline Control & $\mathbf{0 . 7 5 9}$ \\
\hline
\end{tabular}

\section{CONCLUSION}

This study aimed at developing herbal gels for anti acne treatment using seed extracts of Psidium guajava, in Carbopol gel system. Desired formulation of the gel was prepared and evaluated for their physicochemical properties, like color, odour, $\mathrm{pH}$, spreadability, viscosity, foamability and microbial assay. The microbial assay of all the formulations demonstrated better inhibitory activity against acne causing micro organisms probably Propionibacterium acnes, Staphylococcus epidermidis, and Malassezia furfur and stood competitive to the standard marketed formulation. It was concluded that the present research might hopefully bring advancement in the treatment of acnes using herbs as well as in developing herbal formulations for safe and effective management of diseases. Study also concluded that prepared herbal gel possess all essential features of gel formulation for topical application.

\section{ACKNOWLEDGMENTS}

The authors are thankful to the principal, Kamla Nehru College of Pharmacy, Butibori Nagpur, for providing necessary facilities and other technical supports during the preparation of this research article.

\section{CONFLICT OF INTEREST}

The authors report no conflict of interest.

\section{REFERENCES}

1. Rashmi MS. Topical gel: A review. Pharm Rev, 2008; 6:1-3.

2. Wilson, PG, O’Brien, MM, Gadek, PA: Myrtaceae Revisited: A Reassessment of Intrafamilial Groups. American Journal of Botany 2001; 88:2013-2025.

3. Swain, Tony, Ed: Plants in the Development of Modern Medicine. Harvard University Press. ISBN 1968, 0-674- 67330-1.

4. Pelegrini PB, Murad AM, Silva LP, Dos Santos RC, Costa FT, et al Identification of a novel storage glycine-rich peptide from guava (Psidium guajava) seeds with activity against Gram-negative bacteria. Peptides 2008; 29:1271-1279.

5. Metwally AM, Omar AA, Harraz FM, El Sohafy SM, Phytochemical investigation and antimicrobial activity of Psidium guajava $\mathrm{L}$ leaves. Pharmacogn Mag 2010; 6:212-218.

6. Huang CS, Yin MC, Chiu, LC, Antihyperglycemic and antioxidative potential of Psidium guajava fruit in streptozotocin-induced diabetic rats. Food Chem Toxicol 2011; 49:2189-2195.

7. Bontempo P, Doto A, Miceli M, Mita L, Benedetti R, et al. Psidium guajava L. anti-neoplastic effects: induction of apoptosis and cell differentiation. Cell Prolif 2012; 45:22-31.

8. Haida KS, Baron A, Haida KS, Phenolic compounds and antioxidant activity of two varieties of guava and rue. Rev Bras Ciênc Saúde 2011; 28:11-19.

9. Nutritiondata.com. Nutrition facts for common guava. Retrieved August 17, 2010.

10. Castro-Vargas HI, Rodríguez-Varela LI, Ferreira SRS, ParadaAlfonso F, Extraction of phenolic fraction from guava seeds (Psidium guajava L) using supercritical carbon dioxide and cosolvents. J Supercrit Fluids 2010; 51:319-324.

11. Harisaranraj R, Saravanababu S, Suresh K. Antimicrobial properties of selected Indian medicinal plants against acneinducing bacteria. Ethnobot Leaflets, 2010; 14:84-94.

12. Gowda B, Shariff A, Priyadarshini SRB. Formulation and evaluation of topical polyherbal anti-acne gels containing Garciniamangostana and Aloe vera. Pharmacog Mag, 2009; 5:93-99.

13. Hiremath SSP, Dasankoppa FS, Nadaf A, Jamakandi VG, Mulla JS, Sreenivas SA, Sholapur HN, Ahmed A, Nanjunda Swamy NG. Formulation and evaluation of a novel in situ gum based ophthalmic drug delivery system of linezolid. Sci Pharm, 2008; 76:515-532.

14. Panigrahi L, Ghosal SK, Pattnaik S, Maharana L, Barik BB. Effect of permeation enhancers on the release and permeation kinetics of lincomycin hydrochloride gel formulations through mouse skin. Ind J Pharm Sci, 2006; 68205-211.

15. Schoch TJ. Effects of freezing and cold storage on pasted starches. In: Tressler DK, Van Arsdel WD, Copley MJ, eds. The Freezing Preservation of Foods-Vol. 4. Westport: CT, 1968; 4456.

16. Mondal S. Evaluation of the antimicrobial efficacy and safety of pure hands herbal hand sanitizer in hand hygiene and on inanimate objects. The Antiseptic, 2004; 10:55-57. 